Scott D. Mackie

\title{
Eschatology and Exhortation in the Epistle to the Hebrews
}

[Eschatologie und Ermahnung im Hebräerbrief.]

Veröffentlicht auf Englisch.

Scott D. Mackie interpretiert den Hebräerbrief als frühchristliche Ermahnung an eine Gemeinde, die durch das mangelnde

SCOTT D. MACKIE

Eschatology and

Exhortation in the

Zusammengehörigkeitsgefühl ihrer Mitglieder gefährdet wird. Die eschatologischen Konsequenzen von Jesu' Selbst-Opfer und

Erhöhung werden als Ermahnung eingesetzt, um die Identität der Gemeinschaft zu festigen. Die Gemeindeglieder sollen sich

als Geschwister des Sohns begreifen und so zur Nachfolge angeleitet werden.

Epistle to the Hebrews

Scott D. Mackie Born 1964; 2006 PhD Fuller Theological Seminary; currently teaching Biblical Studies at Loyola Marymount University in Los Angeles.

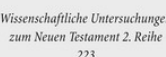

Mohr Siebeck

2007. XI, 284 Seiten. WUNT II 223

ISBN 978-3-16-151566-8

DOI 10.1628/978-3-16-151566-8

eBook PDF $74,00 €$
Jetzt bestellen:

https://mohrsiebeck.com/buch/eschatology-and-exhortation-in-the-epistle-to-the-hebrews-9783161515668?no_cache=1 order@mohrsiebeck.com

Telefon: +49 (0)7071-923-17

Telefax: $+49(0) 7071-51104$ 